\title{
Socioeconomic determinants of cervical cancer screening in Latin America
}

\author{
Samir Soneji ${ }^{1}$ and Natsu Fukui ${ }^{2}$
}

Suggested citation Soneji S, Fukui N. Socioeconomic determinants of cervical cancer screening in Latin America. Rev Panam Salud Publica. 2013;33(3):174-82.

ABSTRACT Objective. To assess the impact of health care access and socioeconomic determinants on Pap smear screening in Latin America.

Methods. Individual-level data was collected from the Demographic and Health Surveys in Bolivia, Brazil, Dominican Republic, Ecuador, Guatemala, Nicaragua, Peru, and Trinidad and Tobago between 1987 and 2008. Multivariate logistic regression analyses were used to identify socioeconomic and health care determinants of two outcomes: knowledge of Pap smears and recent Pap smear screening.

Results. In all countries, the proportion of women with a recent Pap smear screening remained below 55\%. Key determinants of knowledge of Pap smears were age, education, and recent doctor's visit. For recent Pap smear screening, key determinants were wealth and recent doctor's visit. Women were between 1.47 and 3.44 times more likely to have received a recent Pap smear if they had a recent doctor's visit. Even the poorest women with a recent doctor's visit were more likely to screen than the richest women without a recent visit.

Conclusions. These data suggest that visiting a doctor is an important determinant of cervical cancer screening in Latin America. Because screening may coincide with other medical visits, physicians could effectively encourage screening.

Key words Uterine cervical neoplasms; vaginal smears; mass screening; Bolivia; Brazil; Dominican Republic; Ecuador; Guatemala; Nicaragua; Peru; Trinidad and Tobago; Latin America.

The burden of cervical cancer is especially high in Latin America (1), now ranking as the second most common cause of cancer among women in the region. In 2008, incidence in Latin America was four times higher and mortality five times higher than in North America (with incidence and mortality rates of 25 and 11 versus 6 and 2 cases per 100000 respectively) (2). Historically, prevention

\footnotetext{
Dartmouth Institute for Health Policy \& Clinical Practice, Geisel School of Medicine, Dartmouth College, Lebanon, New Hampshire, United States of America. Send correspondence to: Samir Soneji, samir.soneji@dartmouth.edu

2 Geisel School of Medicine, Dartmouth College, Lebanon, New Hampshire, United States of America.
}

efforts largely focused on Pap smears. When conducted effectively, implementation of this type of screening has coincided with significant declines in cervical cancer incidence and mortality. For example, in Iceland, where a costeffective nationwide screening program was initiated in 1964, up-to-date screening coverage had reached $80 \%$ of women 25-69 years old by 1990, leading to a reduction in cervical cancer incidence and mortality of more than $80 \%(3,4)$. In contrast, little progress has been observed in Latin America, where screening rates remain consistently low, even in countries with national screening programs (5-7).
Collective understanding of the possible determinants of cervical cancer screening has grown through studies conducted in several Latin American countries, including Argentina, Costa Rica, Mexico, Nicaragua, and Peru. Women in the region face cultural, logistical, and cost barriers, and their screening is limited by underdeveloped laboratory services. Limited supply of highly trained health care providers and laboratory technicians, insufficient evaluation and follow-up of test results, and limited availability of and access to Pap smears all contribute to low screening and limit progress against the 
burden of cervical cancer (8-14). Health care access and socioeconomic barriers may also limit overall screening coverage and contribute to disparities among population subgroups. A woman's ability and decision to receive screening may depend on her knowledge about Pap smears, health care access, socioeconomic status, and educational levels $(11,12,15-17)$. Two studies in particular-one in Nicaragua, and another in Argentina-found that health care access was independently predictive of having had a recent Pap smear after adjusting for socioeconomic status (12, 16). However, to the best of the authors' knowledge, no study has examined the effect of health care access and socioeconomic determinants in other Latin American settings. The current study aimed to fill that gap by examining the impact of health care access and socioeconomic determinants on Pap smear screening in diverse populations from eight Latin American countries between 1987 and 2008. The main objective of this report is to identify the health care and socioeconomic determinants of Pap smear knowledge and screening. Identifying which determinants are common and which are not may help guide panLatin American public health efforts.

\section{MATERIALS AND METHODS}

\section{Data}

For this cross-sectional study, socioeconomic, health care utilization, and cervical cancer screening data collected in Demographic and Health Surveys (DHS) by the U.S. Agency for International Development (USAID) were analyzed for women aged 21-49 years. DHS are administered to scientifically selected samples of households and women of reproductive age to produce nationally representative data on the population, health, and nutrition of women and children in developing countries worldwide (18). Pertinent information used in this study included the study data year; country; age, sex, type of residence, ethnicity, wealth, and educational attainment of the individuals in each study sample, and whether or not they had had a recent doctor's visit (within the past year); Pap smear use (various criteria by country); and knowledge of Pap smears. Ethnicity was categorized by broad, country-specific groups, according to self-report. Wealth was analyzed based on the DHS wealth index, which categorizes households into five quintiles according to ownership of household items identified as indicators of relative household wealth within each country (19). Educational attainment was divided into four groups: no education ("none"), "primary," "secondary," and "higher" (post-secondary). Residence type was categorized as urban or rural. Recent Pap smear use was analyzed for all eight countries using the following study samples: Bolivia, $n=13159$ (2003), and $n=12789$ (2008); Brazil, $n=9628$ (1996); Dominican Republic, $n=6273$ (1999), $n=17719$ (2002), and $n=20410$ (2007); Ecuador, $n=3480$ (2001); Guatemala, $n=4359$ (1999); Nicaragua, $n=9322$ (2001); Peru, $n=21800$ (1996), $n=21098$ (2000), $n=4407$ (2004), $n=4780$ (2005), $n=5181$ (2006), $n=$ 4992 (2007), and $n=12596$ (2008); and Trinidad and Tobago, $n=2978$ (1987). The total number of survey respondents was 174971 . Table 1 presents individuallevel characteristics of the study population. Analysis of Pap smear knowledge was limited to Bolivia, Peru, and Trinidad and Tobago due to lack of available data for that variable.

\section{Statistical analyses}

Using multivariate logistic regression, the probability for both having knowledge of Pap smears and having a recent Pap smear screening was modeled as a function of age; ethnicity; educational attainment; type of residence; wealth quintile; recent doctor's visit ("yes" or "no"); and year. The results of both sets of statistical models are presented as relative risks (20). A Pap smear was categorized as "recent" based on the standard for each country reflected in the DHS ("in the past year" for Brazil, Dominican Republic, Guatemala, Nicaragua, and Trinidad and Tobago; "in the past two years" for Ecuador; "in the past three years" for Bolivia; and "in the past five years" for Peru). Separate multivariate models were fitted for each country. For all analyses presented in this report, population projection weights calculated by the DHS were incorporated in the data to account for the cluster sampling design. Using the multivariate logistic regression model results, the predicted probability of a woman receiving a recent Pap smear screening was computed as a function of her DHS wealth index quintile, type of residence, and whether she had had a recent doctor's visit (21). All other covariates were set at their modal values (e.g., among Bolivian women, age was set at 31-35 years. education was set as "primary," and the study data year was set as 2003). The R Project for Statistical Computing ("R") (version 2.9.2) was used for all statistical analyses. The Dartmouth College and Dartmouth-Hitchcock Medical Center Committee for the Protection of Human Subjects determined that this research met eligibility criteria for review exemption.

\section{RESULTS}

\section{Patterns in usage and knowledge of Pap smears}

Table 2 presents the proportions of women who reported having 1) a recent Pap smear screening and 2) knowledge of Pap smears, by country and year. In all countries, the proportion who said they had had a recent Pap smear was below 55\%. For example, in the Dominican Republic (2007) the proportion was $49 \%$ (95\% CI, 49\%-50\%), in Bolivia (2008) it was $42 \%$ (95\% CI, 41\%-43\%), and in Peru (2008) it was 52\% (95\% CI, 51\%-53\%). The proportion of women with knowledge of Pap smears grew over time in both Bolivia and Peru, but the level of knowledge was consistently higher in the latter country.

\section{Socieconomic determinants of Pap smear knowledge}

As shown in Table 3, the key determinants of women's knowledge of Pap smears were age, educational attainment, and having had a recent doctor's visit. The likelihood of knowing about Pap smears increased with age (reaching a plateau among 31-35 year olds), and educational attainment. For example, in Bolivia, compared to women with primary education, women with no formal education were $19 \%$ less likely to know about Pap smears (95\% CI, 16\%-22\%), whereas women with secondary and higher education were $11 \%$ (95\% CI, $10 \%-13 \%)$ and $15 \%$ more likely $(95 \% \mathrm{CI}$, $14 \%-17 \%$ ) respectively. In Peru and Bo- 
TABLE 1. Demographic and health care characteristics of sample population for study on socioeconomic determinants of cervical cancer screening in eight Latin American countries, 1987-2008 ${ }^{\mathrm{a}, \mathrm{b}}$

\begin{tabular}{|c|c|c|c|c|c|c|c|c|c|}
\hline Characteristic & $\begin{array}{c}\text { Trinidad } \\
\text { and Tobago } \\
\text { No. }(\%)\end{array}$ & $\begin{array}{c}\text { Guatemala } \\
\text { No. (\%) }\end{array}$ & $\begin{array}{l}\text { Brazil } \\
\text { No. (\%) }\end{array}$ & $\begin{array}{l}\text { Dominican } \\
\text { Republic } \\
\text { No. (\%) }\end{array}$ & $\begin{array}{c}\text { Nicaragua } \\
\text { No. (\%) }\end{array}$ & $\begin{array}{l}\text { Ecuador } \\
\text { No. (\%) }\end{array}$ & $\begin{array}{c}\text { Bolivia } \\
\text { No. (\%) }\end{array}$ & $\begin{array}{l}\text { Per } \\
\text { No. ( }\end{array}$ & \\
\hline$n$ & 2978 & 4359 & 9628 & 44402 & 9322 & 3480 & 25948 & 5305 & \\
\hline \multicolumn{10}{|l|}{ Age group (years) } \\
\hline $21-25$ & $600 \quad(20)$ & (20) & 1544 & 7847 & 1810 & $(21)$ & 4704 & 8847 & (17) \\
\hline $26-30$ & 745 (25) & (21) & 1955 & 8811 & 2021 & 834 (24) & 5412 & 10310 & (19) \\
\hline $31-35$ & 543 (18) & 785 (18) & 1869 (19) & 8193 (18) & 1650 (18) & 664 (19) & 4799 & 9943 & (19) \\
\hline $36-40$ & 441 (15) & 710 (16) & 1713 & 7679 & 1596 & (16) & 4288 & 9136 & (17) \\
\hline $41-45$ & $370 \quad(12)$ & (13) & 1400 & 6495 & 1217 & $396 \quad(11)$ & 3664 & 8112 & (15) \\
\hline $46-49$ & $279 \quad(9)$ & $507 \quad(12)$ & 1147 & 5377 & 1028 (11) & 291 & 3081 & 6706 & (13) \\
\hline \multicolumn{10}{|l|}{ Education } \\
\hline None & $29 \quad(1)$ & 1597 & 719 & 3017 & 1941 & 328 & 1822 & 3268 & (6) \\
\hline Primary & 1606 (54) & 2080 & 3462 (36) & $20881 \quad$ (47) & 3909 (42) & 1746 (50) & 12184 & 18152 & (34) \\
\hline Secondary & 1270 & (14) & 4747 & 12596 (28) & 2532 & 1010 & 6909 & 17674 & (33) \\
\hline Higherd $^{d}$ & $72 \quad(2)$ & (2) & 698 & 7906 & (10) & 396 & 5033 & 13960 & (26) \\
\hline \multicolumn{10}{|l|}{ Residence type } \\
\hline Urban & 1350 & 1443 & 7844 & 27187 & 5261 & 2057 & 16750 & 33163 & (63) \\
\hline Rural & 1628 & 2916 (67) & 1784 & 17215 & 4061 & 1423 (41) & 9198 & 19891 & (37) \\
\hline \multicolumn{10}{|l|}{ Wealth quintile } \\
\hline Poorest & $f$ & 1188 & 1925 & 10163 & $1801 \quad$ (19) & $f$ & 4265 & 11388 & $(21)$ \\
\hline Poorer & $f$ & $(21)$ & 2146 & 9721 & 1794 (19) & $f$ & 4654 & 11149 & (21) \\
\hline Middle & $f$ & 905 (21) & 1993 & 8972 (20) & 1603 (17) & $f$ & 5247 & 7996 & (15) \\
\hline Richer & $f$ & (18) & 1866 & 8003 & 1548 (17) & $f$ & 5773 & 10678 & (20) \\
\hline Richest & $f$ & 563 (13) & 1698 (18) & 6379 (14) & 1343 (14) & $f$ & 6009 (23) & 9787 & (18) \\
\hline \multicolumn{10}{|c|}{ Saw doctor within past year } \\
\hline No & $f$ & 3018 & 3709 & 13051 & 4236 & $f$ & 10186 & 30115 & $(57)$ \\
\hline Yes & $f$ & 1335 & 5916 & 31293 & 5085 & $f$ & 15752 & 22936 & (43) \\
\hline \multicolumn{10}{|l|}{ Ethnicityg } \\
\hline African & 1049 & $--^{h}$ & - & $f$ & $f$ & $f$ & $f$ & \multicolumn{2}{|l|}{-} \\
\hline Black & - & - & 363 & $f$ & $f$ & $f$ & $f$ & \multicolumn{2}{|l|}{-} \\
\hline East Asian & - & - & 40 & $f$ & $f$ & $f$ & $f$ & - & \\
\hline East Indian & 1417 & - & - & $f$ & $f$ & $f$ & $f$ & - & \\
\hline Indian (indigenous) & - & 1614 & $(0)$ & $f$ & $f$ & $f$ & $f$ & - & \\
\hline Ladino & - & $2745 \quad(63)$ & - & $f$ & $f$ & $f$ & $f$ & - & \\
\hline Mixed & $487 \quad(16)$ & - & 5552 & $f$ & $f$ & $f$ & $f$ & - & \\
\hline Other & $24 \quad(1)$ & - & - & $f$ & $f$ & $f$ & $f$ & 500 & (1) \\
\hline Quechua/Aymara & - & - & - & $f$ & $f$ & $f$ & $f$ & 6410 & (12) \\
\hline Spanish & - & - & - & $f$ & $f$ & $f$ & $f$ & 46134 & (87) \\
\hline White & - & - & $3666 \quad(38)$ & $f$ & $f$ & $f$ & $f$ & & - \\
\hline
\end{tabular}

a Source: Demographic and Health Surveys (DHS).

b Sample sizes vary slightly by subgroup due to missing data; percentages may not sum to 100 due to rounding.

c Data for Peru did not include 1996 values because survey respondent race/ethnicity was not ascertained for that year.

d Post-secondary.

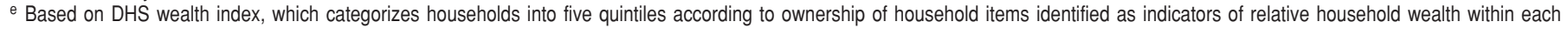
country.

f Data not available for this variable.

9 Self-reported, based on broad, country-specific ethnic groups.

h Not applicable.

livia, women were $4 \%$ (95\% CI, 3\%-5\%) and $14 \%$ less likely (95\% CI, 12\%-17\%) respectively to know about Pap smears if they had not had a recent doctor's visit.

\section{Socioeconomic determinants of recent Pap smear}

As shown in Table 4, the most consistent determinants of having a recent Pap smear screening were wealth and having had a recent doctor's visit. In Bolivia, Brazil, the Dominican Republic, and Guatemala, a strong gradient was observed between wealth and the prob- ability of recent Pap smear screening. For example, in Bolivia, compared to women in the middle wealth quintile, the probability of having had a recent Pap smear screening was $40 \%$ lower in the poorest wealth quintile $(95 \%$ CI, 34\%-44\%); $21 \%$ lower in the second quintile (95\% CI, 16\%-26\%); $12 \%$ higher in the fourth quintile $(95 \% \mathrm{CI}$, $7 \%-18 \%$ ); and $29 \%$ higher in the richest quintile (95\% CI, 24\%-35\%). No consistent wealth gradient was observed with regard to recent Pap smear screening in Nicaragua and Peru. A recent doctor's visit was also a significant determinant of the probability of having a recent Pap smear screening. Compared to women who had not had a recent doctor's visit, the probability of this type of screening among those who had was $48 \%$ higher in Bolivia (95\% CI, 39\%-59\%); $241 \%$ higher in Brazil (95\% CI, 182\%-312\%); 98\% higher in the Dominican Republic (95\% CI, 85\%-113\%); $77 \%$ higher in Guatemala (95\% CI, 36\%-125\%); and $94 \%$ higher in Nicaragua $(95 \%$ CI, $67 \%$ $129 \%$ ). In addition, compared to rural residents, the probability of Pap smear screening among urban residents was higher in Ecuador, Nicaragua, Peru, 
TABLE 2. Proportion of women who reported recent Pap smear usage and knowledge of Pap smears in eight Latin American countries, 1987-2008 ${ }^{\mathrm{a}}$

\begin{tabular}{|c|c|c|c|c|c|c|c|}
\hline \multirow[b]{2}{*}{ Country } & \multirow[b]{2}{*}{ Year } & \multirow[b]{2}{*}{$n$} & \multicolumn{3}{|c|}{ Had recent Pap smear } & \multicolumn{2}{|c|}{ Knew about Pap smears } \\
\hline & & & Time frame & $\%$ & $95 \% \mathrm{Cl}^{\mathrm{b}}$ & $\%$ & $95 \% \mathrm{Cl}$ \\
\hline Trinidad and Tobago & 1987 & 2978 & Past year & 10.4 & $9.3-11.5$ & 57.5 & $55.7-59.2$ \\
\hline Brazil & 1996 & 9628 & Past year & 38.1 & $37.1-39.1$ & c & c \\
\hline Guatemala & 1999 & 4359 & Past year & 26.5 & $25.2-27.9$ & c & c \\
\hline \multirow[t]{3}{*}{ Dominican Republic } & 1999 & 6273 & Past year & 34.5 & $33.3-35.7$ & c & c \\
\hline & 2002 & 17719 & & 45.1 & $44.4-45.8$ & c & c \\
\hline & 2007 & 20410 & & 49.4 & $48.7-50.1$ & c & c \\
\hline Nicaragua & 2001 & 9322 & Past year & 35.8 & $34.9-36.8$ & c & c \\
\hline Ecuador & 2001 & 3480 & Past two years & 28.7 & $27.2-30.2$ & c & c \\
\hline \multirow[t]{2}{*}{ Bolivia } & 2003 & 13159 & Past three years & 36.0 & $35.2-36.9$ & 66.9 & $66.1-67.7$ \\
\hline & 2008 & 12789 & & 42.3 & $41.4-43.1$ & 74.0 & $73.3-74.8$ \\
\hline \multirow[t]{7}{*}{ Peru } & 1996 & 21800 & Past five years & 43.3 & $42.6-43.9$ & 83.1 & $82.6-83.6$ \\
\hline & 2000 & 21098 & & 49.1 & $48.5-49.8$ & 89.3 & $88.9-89.8$ \\
\hline & 2004 & 4407 & & 51.5 & $50.0-53.0$ & 91.9 & $91.1-92.7$ \\
\hline & 2005 & 4780 & & 49.9 & $48.5-51.4$ & 93.7 & $93.0-94.4$ \\
\hline & 2006 & 5181 & & 49.4 & $48.0-50.8$ & 93.1 & $92.4-93.8$ \\
\hline & 2007 & 4992 & & 48.9 & $47.5-50.3$ & 93.8 & $93.1-94.5$ \\
\hline & 2008 & 12596 & & 52.1 & $51.2-53.0$ & 93.9 & $93.5-94.3$ \\
\hline
\end{tabular}

a Source: Demographic and Health Surveys (DHS).
b $\mathrm{Cl}$ : confidence interval.

c Data not available for this variable.

and Trinidad and Tobago. The opposite pattern was observed in Bolivia. Disadvantaged ethnic and racial groups, especially indigenous populations, were less likely to have received a Pap smear screening. For example, compared to Indian (indigenous) women in Guatemala, the probability of screening was $80 \%$ higher among Ladino women (95\% CI, $46 \%-124 \%$ ).

Figure 1 depicts the predicted probability of a recent Pap smear and simultaneously considers the impact of wealth, type of residence, and a recent doctor's vist. All other covariates are set at the modal values for each country shown in Table 4. In all countries, all women who reported a recent doctor's visit, including rural residents, experienced consistently higher probabilities of having a recent Pap smear screening. In addition, in Bolivia, Brazil, the Dominican Republic, and Guatemala, women with greater wealth experienced ever-increasing probabilities of having a recent Pap smear screening (Table 4). This gradient was particularly high for women in Guatemala. For example, among women with a recent doctor's visit, the probability of having a recent Pap smear screening increased from $16 \%$ (95\% CI, $11 \%-23 \%)$ to $43 \%$ (95\% CI, $35 \%-50 \%)$ to $67 \%$ (95\% CI, $57 \%-75 \%$ ) in the poorest, middle, and richest wealth quintiles respectively.

\section{DISCUSSION}

This study has three important findings. First, the results suggest that knowledge of Pap smears may derive indirectly from greater educational attainment. Women with greater education may have greater awareness of and reap greater benefits from preventive medicine, exercise greater autonomy, and face lower cultural barriers to screening $(22,23)$. Second, greater accumulation of wealth increases the likelihood of having a recent Pap smear screening. Women with greater wealth likely experience additional screening opportunities with private practitioners, and face fewer barriers, including transportation and household responsibilities $(16,24)$. Greater wealth may also enable women with a diagnosis of cervical cancer to receive earlier treatment and regular follow-up. Third, in all Latin American countries included in the current study, having a recent doctor's visit was an important determinant of the probability of having a recent Pap smear screening. Adjusting for other socioeconomic covariates, women were between $47 \%$ and $244 \%$ more likely to have received a recent Pap smear screening if they had had a recent doctor's visit compared to those who had not. In Brazil, the Dominican Republic, Nicaragua, and Peru, even the poorest women with a recent doctor's visit were more likely to have received a Pap smear screening than the richest women without a recent visit. This relationship between a recent doctor's visit and screening may operate through several pathways. Screening may coincide with pre- or postnatal care or treatment of an illness, as opposed to women directly seeking preventive care $(15,17)$. Access to health care likely increases considerably for women with health insurance or residing in countries with universal health insurance, as Pap smear screening is one of many preventive health services offered under these coverage programs (25). In addition, health care providers may disseminate Pap smear knowledge and encourage screening, although a recent study of direct clinical observation in Peru found opportunities to educate patients on Pap smear screening were often missed by health care providers (26).

Increasing Pap smear screening in Latin America may depend on two key efforts: raising awareness of preventive care within the community, and encouraging health care providers to advocate more effectively for this type of screening during their patients' visits. The effectiveness of raising awareness within the community has been demonstrated in two recent studies. The Porque Me Quiero, Me Cuido ("Because I like myself, I take care of myself") study set in Oaxaca, Mexico-one of the poorest and most rural states in Mexico-found that women's participation in sexual and reproductive health workshops led to significant increases in their knowledge of and participation in Pap smear screening (24). The Tamizaje y Tratamiento Inmediato (TATI) project set in San Martin, Peru, organized educational events and workshops promoting cervical cancer screening. TATI also found that women's participation in community-based educational sessions had the greatest influence on whether or not they received a Pap smear screening. Furthermore, women who primarily sought care from health care providers, rather than self-treating with home-based remedies, were more likely to undergo Pap smear screening $(13,27)$. Providers can have a large influence on their patients' health care decisions (28) and may be effective in addressing lack of knowledge and cultural barriers, particularly embarrassment, fear of pain, and the relationship 
TABLE 3. Relative risks of having knowledge about Pap smears, according to multivariate logistic regression modeling using demographic and health care data from three Latin American countries, 1987-2008

\begin{tabular}{|c|c|c|c|c|c|c|}
\hline \multirow[b]{2}{*}{ Characteristic } & \multicolumn{2}{|c|}{ Trinidad and Tobago } & \multicolumn{2}{|c|}{ Bolivia } & \multicolumn{2}{|c|}{ Peru } \\
\hline & $\mathrm{RR}^{\mathrm{b}}$ & $95 \% \mathrm{Cl}^{\mathrm{c}}$ & $\mathrm{RR}$ & $95 \% \mathrm{Cl}$ & $\mathrm{RR}$ & $95 \% \mathrm{Cl}$ \\
\hline \multicolumn{7}{|l|}{ Age group (years) } \\
\hline $21-25$ & 0.52 & $0.44-0.62$ & 0.76 & $0.73-0.78$ & 0.95 & $0.94-0.96$ \\
\hline $26-30$ & 0.82 & $0.72-0.92$ & 0.94 & $0.92-0.96$ & 0.99 & $0.98-0.99$ \\
\hline $31-35^{d}$ & 1 & $-\mathrm{e}$ & 1 & - & 1 & - \\
\hline $36-40$ & 1.07 & $0.94-1.21$ & 1.00 & $0.98-1.02$ & 1.01 & $1.00-1.01$ \\
\hline $41-45$ & 1.02 & $0.89-1.16$ & 1.01 & $0.99-1.03$ & 1.01 & $1.00-1.01$ \\
\hline $46-49$ & 0.97 & $0.84-1.13$ & 0.99 & $0.97-1.01$ & 1.01 & $1.00-1.01$ \\
\hline \multicolumn{7}{|l|}{ Education } \\
\hline None & 0.35 & $0.13-0.74$ & 0.81 & $0.78-0.84$ & 0.94 & $0.93-0.96$ \\
\hline Primary ${ }^{d}$ & 1 & - & 1 & - & 1 & - \\
\hline Secondary & 1.48 & $1.38-1.62$ & 1.11 & $1.10-1.13$ & 1.02 & $1.02-1.03$ \\
\hline Higher $^{f}$ & 1.74 & $1.55-1.95$ & 1.15 & $1.14-1.17$ & 1.03 & $1.03-1.04$ \\
\hline \multicolumn{7}{|l|}{ Residence type } \\
\hline Urband & 1 & - & 1 & - & 1 & - \\
\hline Rural & 0.76 & $0.70-0.83$ & 0.97 & $0.95-0.98$ & 0.94 & $0.93-0.95$ \\
\hline \multicolumn{7}{|l|}{ Wealth quintileg } \\
\hline Poorest & $\mathrm{h}$ & - & 0.77 & $0.73-0.80$ & 1.01 & $1.00-1.01$ \\
\hline Poorer & $\mathrm{h}$ & - & 0.91 & $0.89-0.94$ & 1.01 & $1.01-1.02$ \\
\hline Middled $^{d}$ & $\mathrm{~h}$ & - & 1 & - & 1 & - \\
\hline Richer & $\mathrm{h}$ & - & 1.07 & $1.05-1.09$ & 1.02 & $1.01-1.03$ \\
\hline Richest & $\mathrm{h}$ & - & 1.10 & $1.07-1.12$ & 1.02 & $1.01-1.03$ \\
\hline \multicolumn{7}{|l|}{$\begin{array}{l}\text { Saw doctor within past } \\
\text { year }\end{array}$} \\
\hline Nod & $\mathrm{h}$ & - & 1 & - & 1 & - \\
\hline Yes & $\mathrm{h}$ & - & 0.86 & $0.83-0.88$ & 0.96 & $0.95-0.97$ \\
\hline \multicolumn{7}{|l|}{ Yeari } \\
\hline 2000 & $\mathrm{~h}$ & - & $\mathrm{h}$ & - & 0.96 & $0.95-0.97$ \\
\hline 2003 & $\mathrm{~h}$ & - & $1^{d}$ & - & $\mathrm{h}$ & - \\
\hline 2004 & h & - & $\mathrm{h}$ & - & 1.00 & $0.99-1.01$ \\
\hline 2005 & $\mathrm{~h}$ & - & $\mathrm{h}$ & - & 1.02 & $1.01-1.03$ \\
\hline 2006 & $\mathrm{~h}$ & - & $\mathrm{h}$ & - & 1.01 & $1-1.02$ \\
\hline 2007 & $\mathrm{~h}$ & - & $\mathrm{h}$ & - & 1.01 & $1-1.02$ \\
\hline 2008 & $\mathrm{~h}$ & - & 1.08 & $1.07-1.10$ & $1^{d}$ & - \\
\hline \multicolumn{7}{|l|}{ Ethnicity ${ }^{j}$} \\
\hline African & $1^{d}$ & - & $\mathrm{h}$ & - & - & - \\
\hline East Indian & 0.85 & $0.78-0.92$ & $\mathrm{~h}$ & - & - & - \\
\hline Mixed & 1.06 & $0.98-1.15$ & $\mathrm{~h}$ & - & - & - \\
\hline Other & 1.12 & $0.69-1.43$ & $\mathrm{~h}$ & - & 0.89 & $0.84-0.92$ \\
\hline Quechua/Aymara & - & - & $\mathrm{h}$ & - & 0.86 & $0.84-0.88$ \\
\hline Spanish & - & - & $\mathrm{h}$ & - & $1^{d}$ & - \\
\hline
\end{tabular}

a Source: Demographic and Health Surveys (DHS).

${ }^{b}$ RR: relative risk.

${ }^{\circ} \mathrm{Cl}$ : confidence interval.

${ }^{d}$ Reference value.

e Not applicable.

† Post-secondary.

9 Based on the DHS wealth index, which categorizes households into 5 quintiles according to ownership of household items identified as indicators of relative household wealth within each country.

h Data not available for this variable.

" Data for Trinidad and Tobago were only available for a single year (1987), so the covariate "year" was not included in the Trinidad and Tobago model. Data for Peru did not include 1996 values because survey respondent race/ethnicity was not ascertained for that year.

i Self-reported, based on broad, country-specific ethnic groups.

between human papillomavirus (HPV) and cervical cancer. However, a recent study conducted in Peru found few health care providers take advantage of this opportunity (26).

Efficient and equitable national screening programs are necessary steps toward the larger goal of appropriate follow-up of positive findings and early clinical treatment of cervical cancer. Health care systems in the Dominican Republic, Guatemala, and Nicaragua are fragmented, and access is limited to maternal health, which contribute to limited coverage of cytology-based screening (2). Pap smear screening coverage improved throughout the course of the current study, which took place from 1987 to 2008 . For example, in Bolivia, the 2003 Universal Maternal and Child Insurance program (Seguro Universal Materno-Infantil, SUMI) was extended in 2006 to include cervical cancer screening for women up to age 60 years (2). Even among countries with adequate coverage, poor quality of cytology sampling, shortage of trained cytologists, and inadequate follow-up of positive findings reduce the overall effectiveness of screening programs (8, 14). For example, only $25 \%$ of women with an abnormal cytology result received appropriate follow-up care in a 2003 study in San Martin, Peru (29). In addition to limitations in health care systems, the cultural stigma of cervical cancer and its perceived association with multiple untreated sexually transmitted infections (STIs) may limit the effectiveness of screening (29).

This study had several limitations. First, the results are based on self-reported Pap smear usage, which may be subject to recall and response bias. Second, three different standards for defining a Pap smear as "recent" were used ("within one year," "within three years," and "within five years"), according to the schedule of each country's DHS. The optimal screening interval remains an open empirical question and likely depends on previous history of precancerous or cancerous growths, age, sexual history, and genetic and environmental risk factors (30). Third, both recent Pap smear usage and knowledge of Pap smears were not analyzed for all countries studied because information for the latter variable was not included in every national DHS dataset, and the availability of data for all covariates varied across the eight countries studied. To address this gap, separate statistical models were estimated to incorporate as many covariates as possible for each country. Given the limited availability of data on both recent Pap smear usage and Pap smear knowledge, it was not possible to assess the effect of the latter variable on the likelihood of having a Pap smear screening. Fourth, the results about usage and knowledge may not be representative within countries over time and across the Latin American region. Period and cohort effects may influence Pap smear screening patterns, although not necessarily in the same direction. Future analysis of additional DHS data and examination of age group-specific 


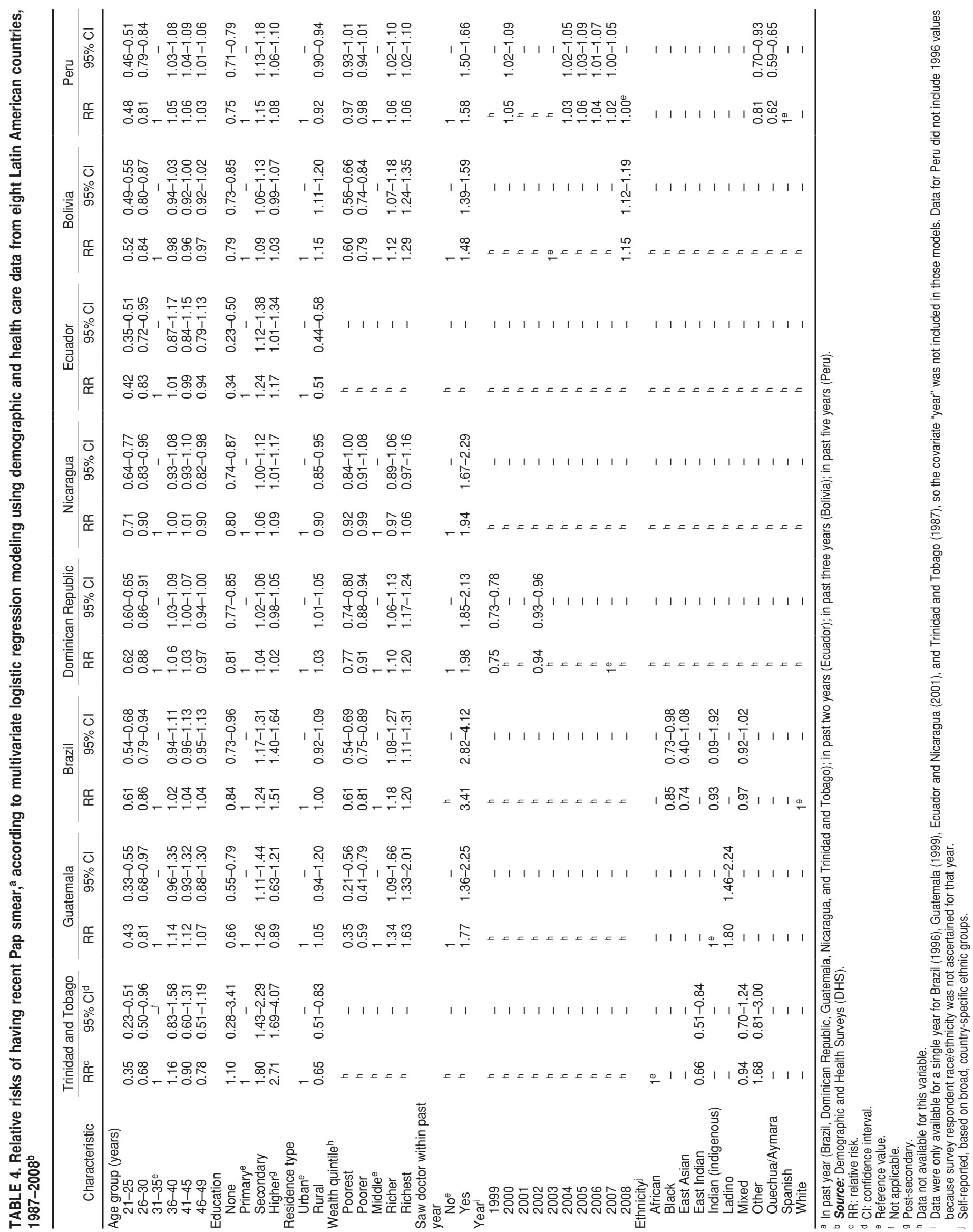


FIGURE 1. Predicted probability of recent ${ }^{\mathrm{a}}$ Pap smear, by country, wealth quintile, type of residence, and recent ${ }^{\mathrm{b}}$ doctor visit (yes or no), based on Demographic and Health Survey (DHS) data from six Latin American countries, 1999-2008c
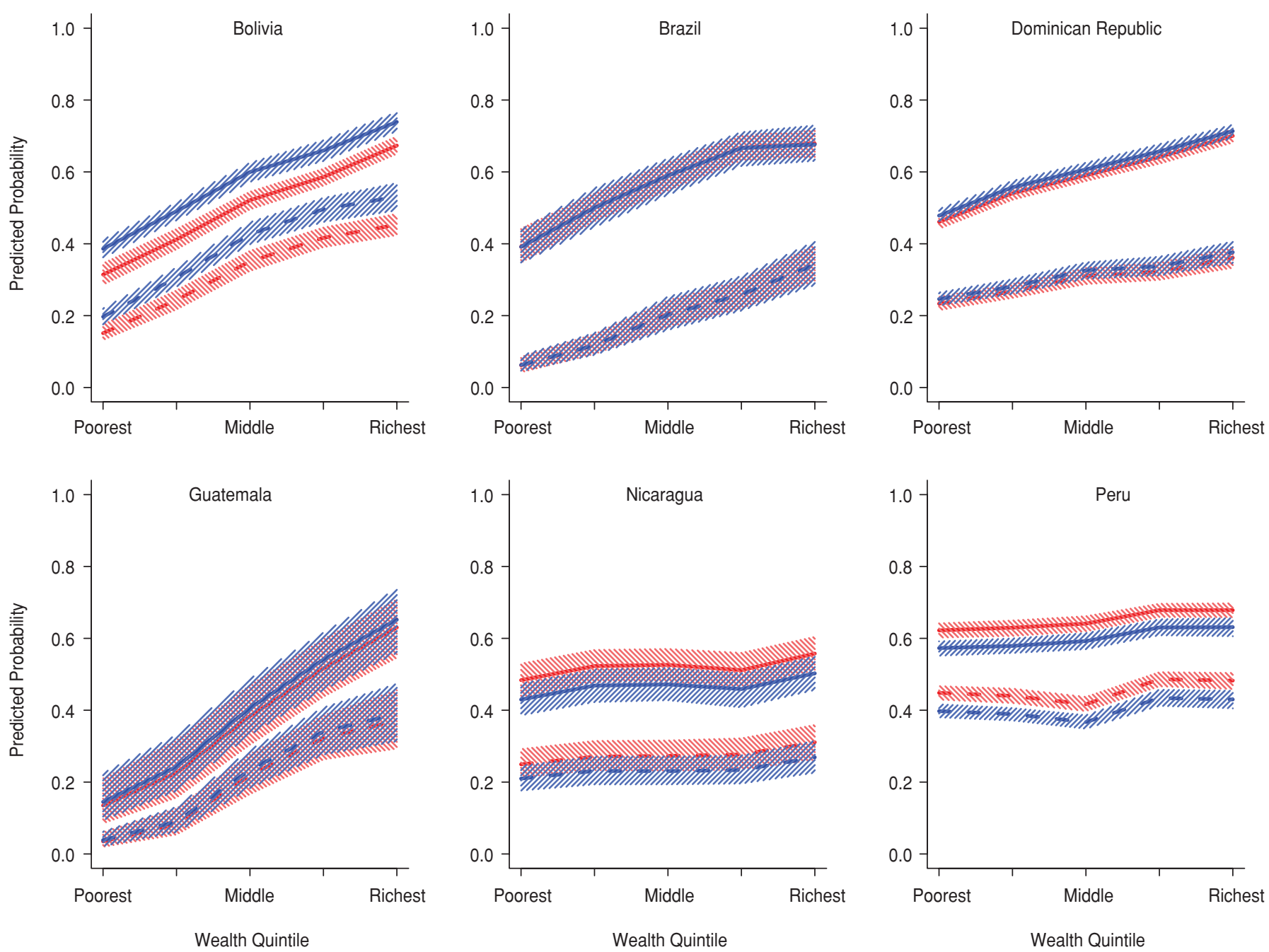

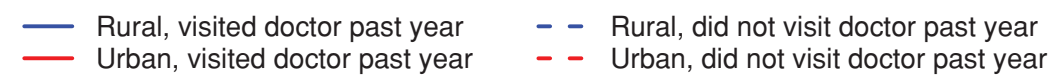

a In past year (Brazil, Dominican Republic, Guatemala, and Nicaragua); in past three years (Bolivia); in past five years (Peru).

b In past year (all countries).

c Shading indicates $95 \%$ confidence intervals for each category.

screening rates over time would help to determine the relative importance of these two effects. In addition, the social and health care factors identified in this study as important determinants of recent Pap smear screening and knowledge of Pap smears may not be as salient for other countries in Latin America. For example, Chile reoriented its cervical cancer screening program in 1987 with an emphasis on cytology quality, followup of women screening positive, and widespread reach across socioeconomic groups (25), resulting in a considerable decline in the national burden of cervical cancer mortality (13 to 7 deaths per 100 000 between 1980 and 2001) (31). Fifth, it was not possible to determine the precise causal nature that underlies the relationship between a recent doctor's visit and screening and the timing of these events. Further research on discussions between patients and doctors would help disentangle this potentially endogenous relationship, especially if coupled with knowledge of the nature and purpose of the doctor's visit (e.g., prenatal care). The problem of endogeneity is a common concern in epidemiologic studies that utilize cross-sectional data (32-34). The covariates included in this study's statistical model, such as wealth quintile and recent doctor's visit, may be correlated with other excluded variables that may also determine whether a woman was recently screened through a Pap smear. Statistical methods such as instrumental variable (IV) estimation could prove useful if the IV is strongly correlated with the potentially endogenous variables and is truly exogenous to the model. Large cross-national studies such as this 
one reveal broad patterns between socioeconomic determinants and health. More focused quasi-experimental and experimental studies, coordinated throughout Latin America, could reveal how these and other determinants produce health and perpetuate health disparities.

Reducing the overall burden of cervical cancer and narrowing historical disparities are two paramount public health goals in cervical cancer. How to optimally achieve these goals remains an open question, especially in resourcelimited settings. Pre- and perinatal care visits may represent two important and currently underutilized opportunities for health care providers to educate their patients about Pap smears. However, increasing the availability and accessibility of Pap smears may provide no additional benefit if pathology services remain underdeveloped, and follow-up of positive screenings remain low. Other techniques, such as simple visual inspection, visual inspection with acetic acid, or HPV DNA testing, may prove as or more effective $(35,36)$. In addition, increased screening efforts may result in decreased resources for treatment and HPV vaccination (37). As new screening modalities, vaccinations, and treatments become available, the focus of strategies to reduce cervical cancer may shift away from Pap smears. However, the socioeconomic determinants identified in the current study may continue to perpetuate disparities unless directly addressed by antipoverty and education programs.

\section{REFERENCES}

1. Yang BH, Bray FI, Parkin DM, Sellors JW, Zhang Z. Cervical cancer as a priority for prevention in different world regions: an evaluation using years of life lost. Int J Cancer. 2004; 109(3):418-24.

2. International Agency for Research on Cancer Working Group on the Evaluation of CancerPreventive Strategies. Cervix cancer screening. IARC handbooks of cancer prevention. Vol. 10. Lyon, France: IARC; 2005. Available from: http://www.iarc.fr/en/publications/pdfsonline/prev/handbook10/handbook10-cover. pdf

3. Lăără E, Day NE, Hakama M. Trends in mortality from cervical cancer in the Nordic countries: association with organised screening programmes. Lancet. 1987;1(8544):1247-9.

4. Sigurdsson K. The Icelandic and Nordic cervical screening programs: trends in incidence and mortality rates through 1995 . Acta Obstet Gynecol Scand. 1999;78(6):478-85.

5. Arrossi S, Sankaranarayanan R, Parkin DM. Incidence and mortality of cervical cancer in Latin America. Salud Publica Mex. 2003;45 Suppl 3:S306-14.

6. Bosetti C, Malvezzi M, Chatenoud L, Negri E, Levi F, La Vecchia C. Trends in cancer mortality in the Americas, 1970-2000. Ann Oncol. 2005;16(3):489-511.

7. Sankaranarayanan R, Budukh AM, Rajkumar R. Effective screening programmes for cervical cancer in low- and middle-income developing countries. Bull World Health Organ. 2001;79(10):954-62.

8. Koss LG. The Papanicolaou test for cervical cancer detection. A triumph and a tragedy. JAMA. 1989;261(5):737-43.

9. Herrero R, Brinton LA, Reeves WC, Brenes MM, de Britton RC, Gaitan E, et al. Screening for cervical cancer in Latin America: a casecontrol study. Int J Epidemiol. 1992;21(6): 1050-6.

10. Bishop A, Wells E, Sherris J, Tsu V, Crook B. Cervical cancer: evolving prevention strate- gies for developing countries. Reprod Health Matters. 1995;3(6):60-71.

11. Lazcano-Ponce EC, Moss S, Alonso de Ruíz $\mathrm{P}$, Salmerón Castro J, Hernández Avila M. Cervical cancer screening in developing countries: why is it ineffective? The case of Mexico. Arch Med Res. 1999;30(3):240-50.

12. Claeys P, Gonzalez C, Gonzalez M, Page H, Bello RE, Temmerman M. Determinants of cervical cancer screening in a poor area: results of a population-based survey in Rivas, Nicaragua. Trop Med Int Health. 2002;7(11):935-41. tion in Peru: lessons learned from the TATI demonstration project. Washington: Pan American Health Organization; 2006.

14. Murillo R, Almonte M, Pereira A, Ferrer E, Gamboa OA, Jerónimo J, et al. Cervical cancer screening programs in Latin America and the Caribbean. Vaccine. 2008;26 Suppl 11:L37-48.

15. Watkins MM, Gabali C, Winkleby M, Gaona E, Lebaron S. Barriers to cervical cancer screening in rural Mexico. Int J Gynecol Cancer. 2002;12(5):475-9.

16. Arrossi S, Ramos S, Paolino M, Sankaranarayanan R. Social inequality in Pap smear coverage: identifying under-users of cervical cancer screening in Argentina. Reprod Health Matters. 2008;16(32):50-8.

17. Paz Soldan VA, Lee FH, Carcamo C, Holmes KK, Garnett GP, Garcia P. Who is getting Pap smears in urban Peru? Int J Epidemiol. 2008; 37(4):862-9.

18. Rutstein SO. Effects of preceding birth intervals on neonatal, infant and under-five years mortality and nutritional status in developing countries: evidence from the demographic and health surveys. Int J Gynaecol Obstet. 2005;89 Suppl 1:S7-24.

19. Rutstein SO, Johnson K. The DHS Wealth Index. DHS Comparative Reports No. 6. Calverton, MD: ORC Macro; 2004.

20. Zhang J, Yu KF. What's the relative risk? A method of correcting the odds ratio in cohort
13. Luciani S, Winkler J. Cervical cancer preven-
In conclusion, this study found several socioeconomic and health care factors that are important determinants of Pap smear knowledge and screening across eight countries in Latin America. Efforts to reduce poverty through education may increase Pap smear knowledge and use, and efforts to increase access to health care providers may be just as important as greater wealth accumulation.

Funding. This work was supported by funding from the National Cancer Institute (NCI) (grant no. RC2CA148259) at the National Institutes of Health (NIH), an agency of the U.S. Department of Health and Human Services.

\section{Conflict of interest. None.}

studies of common outcomes. JAMA. 1998; 280(19):1690-1.

21. Imai K, King G, Lau O. Toward a common framework for statistical analysis and development. J Comput Graph Stat. 2008;17(4): 892-913.

22. Reyes-Ortiz CA, Camacho ME, Amador LF, Velez LF, Ottenbacher KJ, Markides KS. The impact of education and literacy levels on cancer screening among older Latin American and Caribbean adults. Cancer Control. 2007;14(4):388-95.

23. Sabates R, Feinstein L. The role of education in the uptake of preventative health care: the case of cervical screening in Britain. Soc Sci Med. 2006;62(12):2998-3010.

24. Givaudan M, Leenen I, Pick S, Angulo A, Poortinga YH. Enhancement of underused cervical cancer prevention services in rural Oaxaca, Mexico. Rev Panam Salud Publica. 2008;23(2):135-43.

25. Reyes-Ortiz CA, Velez LF, Camacho ME, Ottenbacher KJ, Markides KS. Health insurance and cervical cancer screening among older women in Latin American and Caribbean cities. Int J Epidemiol. 2008;37(4):870-8.

26. Bayer AM, Nussbaum L, Cabrera L, PazSoldan VA. Missed opportunities for health education on Pap smears in Peru. Health Educ Behav. 2011;38(2):198-209.

27. Winkler J, Bingham A, Coffey P, Handwerker WP. Women's participation in a cervical cancer screening program in northern Peru. Health Educ Res. 2008;23(1):10-24.

28. Bingham A, Bishop A, Coffey P, Winkler J, Bradley J, Dzuba I, et al. Factors affecting utilization of cervical cancer prevention services in low-resource settings. Salud Publica Mex. 2003;45 Suppl 3:S408-16.

29. Gage JC, Ferreccio C, Gonzales M, Arroyo R, Huivín M, Robles SC. Follow-up care of women with an abnormal cytology in a low-resource setting. Cancer Detect Prev. 2003;27(6):466-71. 
30. Kulasingam SL, Havrilesky L, Ghebre R, Myers ER. Screening for cervical cancer: a decision analysis for the U.S. Preventive Services Task Force. Report No. 11-05157-EF-1. Rockville, MD: Agency for Healthcare Research and Quality; 2011.

31. Sepúlveda C, Prado R. Effective cervical cytology screening programmes in middle-income countries: the Chilean experience. Cancer Detect Prev. 2005;29(5):405-11.

32. Bollen KA, Guilkey DK, Mroz TA. Binary outcomes and endogenous explanatory variables: tests and solutions with an application to the demand for contraceptive use in Tunisia. Demography. 1995;32(1):111-31.
33. Ruel MT, Menon P. Child feeding practices are associated with child nutritional status in Latin America: innovative uses of the demographic and health surveys. J Nutr. 2002; 132(6):1180-7.

34. McQuestion M. Endogenous social effects on intimate partner violence in Colombia. Soc Sci Res. 2003;32(2):335-45.

35. Mandelblatt JS, Lawrence WF, Gaffikin L, Limpahayom KK, Lumbiganon P, Warakamin $\mathrm{S}$, et al. Costs and benefits of different strategies to screen for cervical cancer in lessdeveloped countries. J Natl Cancer Inst. 2002; 94(19):1469-83.
36. Sherlaw-Johnson C, Gallivan S, Jenkins D. Evaluating cervical cancer screening programmes for developing countries. Int J Cancer. 1997;72(2):210-6.

37. Jahn A. Screening-the Trojan horse in preventive medicine? Trop Med Int Health. 2002;7(4):295-7.

Manuscript received on 29 January 2012. Revised version accepted for publication on 18 December 2012.

RESUMEN Objetivo. Evaluar las repercusiones del acceso a la atención de salud y de los determinantes socioeconómicos sobre la detección sistemática del cáncer cervicouterino con la prueba de Papanicolaou en América Latina.

Determinantes Métodos. Se recopilaron datos individuales a partir de Encuestas de Demografía y socioeconómicos de las Salud realizadas en Bolivia, Brasil, Ecuador, Guatemala, Nicaragua, Perú, República Dominicana y Trinidad y Tobago entre 1987 y 2008. Se utilizaron análisis de regresión logística con múltiples variables para identificar los determinantes socioeconómicos y de atención de salud de dos resultados: el conocimiento de la existencia de la prueba de Papanicolaou y el tamizaje reciente con esta prueba.

cáncer cervicouterino en América Latina

Resultados. En todos los países, la proporción de mujeres sometidas recientemente a la detección sistemática del cáncer cervicouterino con la prueba de Papanicolaou se mantuvo por debajo de 55\%. Los determinantes fundamentales del conocimiento de la existencia de la prueba de Papanicolaou fueron edad, escolaridad y haber acudido recientemente a una consulta médica. En el caso del tamizaje reciente con esta prueba, los determinantes fundamentales fueron riqueza y consulta médica reciente. La probabilidad de que se hubiera realizado recientemente la prueba de Papanicolaou a una mujer fue de 1,47 a 3,44 veces mayor entre las mujeres que habían acudido al médico recientemente. Incluso las mujeres más pobres que habían acudido al médico recientemente presentaban mayor probabilidad de haber sido sometidas a la prueba que las mujeres más ricas sin consulta médica reciente.

Conclusiones. Estos datos indican que acudir al médico es un determinante importante de las pruebas de detección sistemática del cáncer cervicouterino en América Latina y, dado que estas pueden coincidir con otras consultas médicas, los médicos están en condiciones de promoverlas con eficacia.

Palabras clave Neoplasias del cuello uterino; frotis vaginal; tamizaje masivo; Bolivia; Brasil; República Dominicana; Ecuador; Guatemala; Nicaragua; Perú; Trinidad y Tobago; América Latina. 